\title{
INVERS MOORE-PENROSE PADA MATRIKS ATAS ALJABAR MAX-PLUS TERSIMETRI
}

\author{
Suroto \\ Jurusan Matematika, Universitas Jenderal Soedirman, Jl. Dr. Soeparno Karangwangkal, Purwokerto \\ Email: suroto@unsoed.ac.id
}

\begin{abstract}
This paper discusses the Moore-Penrose inverse in the symmetrized max-plus algebraic matrix. The definition of the Moore-Penrose inverse in the symmetrized max-plus algebra sense is adopted from the Moore-Penrose inverse in conventional algebra. The "equal" relation in conventional algebra is replaced by a "balanced" relation in symmetrized max-plus algebra sense. The existence of the Moore-Penrore inverse is shown by using a function that corresponds between the symmetrized max-plus algebra and conventional algebra. The results obtained are the existence and some properties of the Moore-Penrose inverse in the symmetrized max-plus algebraic matrix. These results can potentially be utilized in determining the solution of linear balance systems that have similarly role as linear equation systems in the conventional algebra sense.
\end{abstract}

Keywords: symmetrized max-plus algebra, Moore-Penrose inverse, matrix

\section{ABSTRAK}

Pada makalah ini dibahas tentang invers Moore-Penrose pada matriks atas aljabar max-plus tersimetri. Pendefinisian invers Moore-Penrose atas aljabar max-plus tersimetri dilakukan dengan mengadopsi invers Moore-Penrose pada aljabar konvensional. Relasi "sama dengan" pada aljabar konvensional diganti peranannya dengan relasi "setimbang" pada aljabar max-plus tersimetri. Eksistensi invers Moore-Penrose ditunjukkan dengan memanfaatkan suatu fungsi yang mengkorespondensikan aljabar max-plus tersimetri dengan aljabar konvensional. Hasil yang diperoleh adalah bentuk dan beberapa sifat invers Moore-Penrose pada matriks atas aljabar max-plus tersimetri. Hasil ini berpotensi dapat dimanfaatkan untuk menentukan solusi dari sistem kesetimbangan linier atas aljabar max-plus tersimetri yang memiliki kemiripan peranan dengan sistem persamaan linier pada aljabar konvensional.

Kata kunci: Aljabar max-plus tersimetri, invers Moore-Penrose, matriks

Dikirim: 24 Juni 2021; Diterima: 31 Agustus 2021; Dipublikasikan: 30 September 2021

Cara sitasi: Suroto. (2021). Invers moore-penrose pada matriks atas aljabar max-plus tersimetri. Teorema: Teori dan Riset Matematika, 6(2), 198-209. DOI: http://dx.doi.org/10.25157/teorema.v6i2.5514 


\section{PENDAHULUAN}

Pada pembahasan aljabar linier, salah satu topik yang dibahas adalah invers matriks. Untuk suatu matriks persegi $A_{n \times n}$, invers matriks $A$ didefinisikan sebagai matriks $A^{-1}$ yang memenuhi $A A^{-1}=$ $A^{-1} A=I_{n}$ dengan $I_{n}$ merupakan matriks identitas berordo $n$ (Golub \& Van, 2013). Apabila determinan dari matriks persegi $A$ tidak nol maka eksistensi $A^{-1}$ terjamin ada. Invers matriks persegi ini memiliki peranan yang sangat penting pada penentuan solusi sistem persamaan linier. Pembahasan mengenai sistem persamaan linier sudah banyak dilakukan Hogben (2007) dan Beezer (2015). Untuk sistem persamaan linier $A x=b$ dengan $A^{-1}$ ada, maka sistem persamaan linier tersebut memiliki solusi $x=$ $A^{-1} b$.

Pada pembahasan invers pada matriks $A_{m \times n}$, maka invers matriks $A$ tersebut sering dinamakan dengan invers Moore-Penrose dan dinotasikan dengan $A^{+}$. Pada tahun 1973, pembahasan awal mengenai invers Moore-Penrose pada aljabar konvensional dilakukan (Ben-Israel \& Greville, 2003). Invers Moore-Penrose dapat digunakan untuk menentukan penyelesaian sistem persamaan linier $A x=$ $b$ dengan $A$ berordo $m \times n$. Untuk sistem persamaan linier $A x=b$ dengan $A^{+}$adalah invers MoorePenrose dari $A$, maka $x=A^{+} b$ adalah solusi pendekatan untuk sistem persamaan linier. Pembahasan mengenai penggunaan invers Moore-Penrose pada sistem persamaan linier sudah dilakukan (Campbell \& Meyer, 2009).

Penelitian mengenai invers Moore-Penrose atas struktur aljabar yang lain sudah banyak dibahas. Pembahasan invers Moore-Penrose atas daerah integral sudah dilakukan Bhaskara (1983); Manjunatha \& Bapat (1992); dan Bapat et al., (1990). Selanjutnya pembahasan invers Moore-Penrose atas daerah semiring sudah dilakukan (Farid et al., 2013). Selain itu, invers Moore-Penrose atas ring dan lapangan juga sudah dilakukan pembahasan (Xu \& Chen, 2019; Pearl, 1968). Penelitian terkait invers MoorePenrose atas himpunan fuzzy sudah dilakukan (Pradhan \& Pal, 2014).

Pada pembahasan aljabar max-plus, pendefinisian invers matriks persegi dilakukan secara analog seperti pada matriks konvensional dalam aljabar linier. Eksistensi invers matriks pada aljabar max-plus dapat ditentukan dengan memanfaatkan matriks permutasi dan diagonal. Pembahasan invers matriks atas aljabar max-plus memiliki keterbatasan dan tidak dapat dilakukan seperti halnya pada matriks konvensional. Hal ini dikarenakan masalah tidak adanya invers penjumlahan untuk setiap elemen pada aljabar max-plus, terkecuali elemen nol (Baccelli, 1992).

Salah satu perbedaan utama antara aljabar max-plus dengan aljabar konvensional adalah tidak adanya invers penjumlahan untuk setiap elemen pada aljabar max-plus, kecuali untuk elemen nol. Proses simetrisasi dapat dilakukan pada aljabar max-plus untuk memperoleh bentuk negatif dari setiap elemen pada aljabar max-plus. Bentuk negatif ini tidak dapat langsung berperan sebagai invers penjumlahan, tetapi hanya berperan untuk memperoleh bentuk setimbang (balance). Hasil dari proses simetrisasi aljabar max-plus dinamakan aljabar max-plus tersimetri, dan selanjutnya notasikan dengan $\mathbb{S}$ (Baccelli, 1992).

Pembahasan mengenai invers Moore-Penrose matriks atas $\mathbb{S}$ belum dilakukan. Tujuan penelitian ini adalah menentukan eksistensi dan beberapa sifat invers Moore-Penrose pada matriks atas $\mathbb{S}$. Hasil yang diperoleh pada penelitian ini berpotensi dapat dimanfaatkan untuk menentukan solusi dari sistem kesetimbangan linier atas $\mathbb{S}$. Sistem kesetimbangan linier pada $\mathbb{S}$ memiliki kemiripan peranan dengan sistem persamaan linier pada aljabar konvensional. Selain itu, juga berpotensi dikembangkan pada konstruksi invers Moore-Penrose dengan menggunakan beberapa dekomposisi matriks atas $\mathbb{S}$.

Artikel ini disajikan dengan susunan sistematika yakni bagian awal menyajikan pendahuluan yang merupakan motivasi dan kebaruan dari penelitian. Bagian kedua menyajikan pembahasan aljabar max-plus tersimetri dan invers Moore-Penrose pada matriks konvensional yang merupakan landasan pustaka penelitian. Bagian utama dari artikel ini disajikan pada hasil dan pembahasan yang berisi tentang eksistensi dan beberapa sifat invers Moore-Penrose dari matriks atas aljabar max-plus tersimetri. Bagian terakhir menyajikan kesimpulan dan rekomendasi untuk penelitian selanjutnya. 


\section{Aljabar Max-Plus Tersimetri}

Diberikan $\mathbb{R}$ adalah himpunan semua bilangan riil. Aljabar max-plus adalah struktur aljabar dari sistem matematika $\mathbb{R}_{\text {max }}=\mathbb{R} \cup\{-\infty\}$ yang dilengkapi operasi $\oplus$ yakni maksimum (dinotasikan max) dan operasi $\otimes$ yakni penjumlahan biasa (dinotasikan + ) (Baccelli, 1992). Salah satu perbedaan utama antara aljabar max-plus dengan aljabar konvensional adalah tidak adanya invers penjumlahan untuk setiap elemen pada aljabar max-plus, kecuali untuk elemen nol. Proses simetrisasi dapat dilakukan pada aljabar max-plus untuk memperoleh bentuk negatif dari setiap elemen pada aljabar max-plus. Bentuk negatif ini tidak dapat berperan sebagai invers penjumlahan, tetapi hanya berperan untuk memperoleh bentuk setimbang. Simetrisasi pada aljabar max-plus dapat dianalogikan dengan perluasan himpunan semua bilangan cacah $\mathbb{N}_{0}$ menjadi himpunan semua bilangan bulat $\mathbb{Z}$ pada aljabar konvensional.

Proses simetrisasi dilakukan seperti pada pembentukan kuosien $\mathbb{N}_{0} \times \mathbb{N}_{0}$ terhadap relasi sama dengan (dinotasikan $=$ ) untuk menghasilkan $\mathbb{Z}$. Selanjutnya, relasi sama dengan diganti dengan relasi setimbang yang didefinisikan seperti berikut ini.

Definisi 1. (Baccelli, 1992) Diberikan $u=(a, b), v=(c, d) \in \mathbb{R}_{\max } \times \mathbb{R}_{\max }$. Elemen $u$ dikatakan berelasi setimbang dengan $v$ (dinotasikan $u \nabla v$ ) apabila $a \oplus d=b \oplus c$.

Suatu relasi dikatakan ekuivalensi apabila bersifat refleksif, simetris dan transitif. Pembentukan kuosien atas suatu relasi dapat dilakukan apabila relasi tersebut merupakan suatu relasi ekuivalensi. Relasi setimbang $\nabla$ pada Definisi 1 bersifat refleksif, karena untuk setiap $(a, b) \in$ $\mathbb{R}_{\max } \times \mathbb{R}_{\max }$ berlaku $(a, b) \nabla(a, b)$, yakni $a \oplus b=\max (a, b)=\max (b, a)=b \oplus a$. Selanjutnya, relasi setimbang tersebut juga bersifat simetris karena untuk setiap $(a, b),(c, d) \in$ $\mathbb{R}_{\max } \times \mathbb{R}_{\max }$, jika $(a, b) \nabla(c, d)$ yakni $a \oplus d=\max (a, d)=\max (b, c)=b \oplus c$ maka mengakibatkan $(c, d) \nabla(a, b)$ yakni $c \oplus b=\max (c, b)=\max (d, a)=d \oplus a$. Sementara itu, relasi setimbang $\nabla$ tidak bersifat transitif karena terdapat $(5,0)$, (5,5), (1,5) $\in \mathbb{R}_{\max } \times \mathbb{R}_{\max }$ dengan $(5,0) \nabla(5,5)$ dan $(5,5) \nabla(1,5)$ akan tetapi $(5,0) \forall(1,5)$. Dengan demikian, relasi setimbang $\nabla$ bukan merupakan relasi ekuivalensi. Akibatnya, tidak bisa dibentuk kuosien atas relasi setimbang.

Selanjutnya didifenisikan relasi $\mathcal{B}$ yang masih berkaitan dengan relasi $\nabla$ dan merupakan suatu relasi ekuivalensi, seperti berikut:

Definisi 2. (Baccelli, 1992) Diberikan $u=(p, q), v=(r, s) \in \mathbb{R}_{\max } \times \mathbb{R}_{\max }$. Elemen u berelasi $\mathcal{B}$ dengan $v$ (dinotasikan dengan $u \mathcal{B} v$ ) yakni

$$
(p, q) \mathcal{B}(r, s) \text { apabila }\left\{\begin{array}{l}
(p, q) \nabla(r, s), \text { untuk } p \neq q \text { dan } r \neq s \\
(p, q)=(r, s), \quad \text { untuk lainnya }
\end{array}\right.
$$

Karena $\mathcal{B}$ merupakan relasi ekuivalensi, maka dapat dibentuk kuosien atas relasi $\mathcal{B}$. Himpunan kuosien yang terbentuk atas relasi ekuivalensi $\mathcal{B}$ dinotasikan dengan $\mathbb{S}$ dan dinamakan aljabar max-plus tersimetri (symmetrized max-plus algebra).

Operator setimbang (dinotasikan ( $)^{\bullet}$ ) dan minus (dinotasikan $\ominus$ ) pada $\mathbb{R}_{\max } \times \mathbb{R}_{\max }$ masing-masing didefinisikan dengan $(a, b)^{\bullet}=(a \oplus b, a \oplus b)$ dan $\ominus(a, b)=(b, a)$ untuk setiap $(a, b) \in \mathbb{R}_{\max } \times \mathbb{R}_{\max }$. Selanjutnya untuk setiap $u, v \in \mathbb{S}$ berlaku $u^{\bullet}=(\ominus u)^{\bullet}=\left(u^{\bullet}\right)^{\bullet}$, $u \otimes v^{\bullet}=u^{\bullet} \otimes v=(u \otimes v)^{\circ}, \quad \ominus(\ominus u)=u, \quad \ominus(u \oplus v)=(\ominus u) \oplus(\ominus v)$ dan $\ominus$ $(u \otimes v)=(\ominus u) \otimes v=u \otimes(\ominus v)$.

Beberapa notasi yang berkaitan dengan aljabar max-plus tersimetri yakni $\mathbb{S}^{\oplus}$ adalah himpunan semua elemen positif atau nol pada $\mathbb{S}, \mathbb{S}^{\ominus}$ adalah himpunan semua elemen negatif atau nol pada $\mathbb{S}, \mathbb{S}^{\bullet}$ adalah himpunan semua elemen setimbang pada $\mathbb{S}, \mathbb{S}^{\vee}=\mathbb{S}^{\oplus} \cup \mathbb{S}^{\ominus}$ adalah himpunan semua elemen bertanda pada $\mathbb{S}$ dan $\mathbb{S}_{*}^{\vee}=\mathbb{S}-\mathbb{S}^{*}$ adalah himpunan semua elemen bertanda tanpa elemen nol. Selanjutnya pada $\mathbb{S}$ juga berlaku sifat $\mathbb{S}^{\oplus} \cup \mathbb{S}^{\ominus} \cup \mathbb{S}^{\bullet}=\mathbb{S}$ dan $\mathbb{S}^{\oplus} \cap$ $\mathbb{S}^{\ominus} \cap \mathbb{S}^{\bullet}=\{\overline{(\mathcal{E}, \mathcal{\varepsilon})}\}$. 
Teorema 3. (Baccelli, 1992) Untuk $p, q \in \mathbb{R}_{\max }$ berlaku

1. $p \oplus(\ominus q)=p$, untuk $p>q$

2. $p \oplus(\ominus q)=\ominus q$, untuk $p<q$

3. $p \oplus(\ominus p)=p^{\bullet}$

Relasi $\nabla$ pada aljabar max-plus tersimetri selanjutnya akan memainkan peranan yang mirip dengan relasi $=$ pada aljabar konvensional. Beberapa sifat dasar dari relasi setimbang pada aljabar max-plus tersimetri dijelaskan pada teorema berikut ini.

Teorema 4. (Baccelli, 1992) Untuk setiap $p, q, r, s \in \mathbb{S}$ berlaku

1. $p \nabla p$

2. $p \nabla q$ jika dan hanya jika $q \nabla p$

3. $p \nabla q$ jika dan hanya jika $p \ominus q \nabla \mathcal{E}$

4. Jika $p \nabla q$ dan $r \nabla s$ maka $p \oplus r \nabla q \oplus s$

5. Jika $p \nabla q$ maka $p \otimes r \nabla q \otimes r$

Pada aljabar konvensional berlaku $p-r=q$ jika dan hanya jika $p=q+r$. Selanjutnya, sifat tersebut diadopsi pada aljabar max-plus tersimetri yang disajikan pada teorema berikut ini.

Teorema 5. (Schutter, 1996) Untuk setiap $p, q, r \in \mathbb{S}$, berlaku $p \ominus r \nabla q$ jika dan hanya jika $p \nabla q \oplus r$

Pada aljabar konvensional, berlaku sifat substitusi yakni jika $p=q$ dan $c \times p=b$ maka berlaku $c \times q=b$. Sifat substitusi ini tidak bisa diadopsi secara langsung pada aljabar max-plus tersimetri. Untuk setiap $p, q, c, b \in \mathbb{S}$, jika $p \nabla q, c \otimes p \nabla b$ maka belum tentu berlaku $c \otimes q \nabla b$. Sifat substitusi yang berlaku pada aljabar max-plus tersimetri hanyalah sifat substitusi lemah yang disajikan pada teorema berikut ini.

Teorema 6. Substitusi Lemah (Schutter, 1996) Apabila $p \nabla q, c \otimes p \nabla b$ dengan $p \in \mathbb{S}^{\vee}$ maka $c \otimes q \nabla b$

Berdasarkan sifat substitusi lemah pada aljabar max-plus tersimetri, selanjutnya dapat diturunkan sifat transitif lemah seperti berikut.

Teorema 7. Transitif Lemah (Schutter, 1996) Jika $a \nabla p, p \nabla b$ dengan $p \in \mathbb{S}^{\vee}$ maka $a \nabla b$.

Selain itu, berdasarkan sifat substitusi lemah juga dapat diturunkan sifat reduksi setimbang pada aljabar max-plus tersimetri yang disajikan pada teorema berikut ini.

Teorema 8. Reduksi Setimbang (Schutter, 1996) Jika $p \nabla q$ dengan $p, q \in \mathbb{S}^{\vee}$ maka $p=q$.

Relasi setimbang pada $\mathbb{S}$ dapat diperluas pada matriks atas $\mathbb{S}$. Secara umum, matriks atas $\mathbb{S}$ didefinisikan secara analog seperti pada matriks konvensional. Bentuk umum dari matriks atas $\mathbb{S}$ yang berordo $m \times n$ adalah $A=\left[a_{i j}\right]$ dengan $a_{i j} \in \mathbb{S}$ untuk setiap $i=1,2, \ldots, m$ dan $j=$ $1,2, \ldots, n$. Operasi aljabar pada matriks atas $\mathbb{S}$ juga memiliki kemiripan dengan operasi aljabar pada matriks konvensional dengan menyesuaikan operasi entri-entrinya dengan operasi pada $\mathbb{S}$.

Kesetimbangan dua buah matriks pada aljabar max-plus tersimetri didefinisikan berikut.

Definisi 9. (Schutter, 1996) Untuk matriks $A=\left[a_{i j}\right], B=\left[b_{i j}\right] \in \mathbb{S}^{m \times n}, A \nabla B$ jika $a_{i j} \nabla b_{i j}$ untuk $i=1,2, \ldots, m$ dan $j=1,2, \ldots, n$.

Beberapa sifat relasi setimbang pada $\mathbb{S}$ dapat diperluas pada matriks atas $\mathbb{S}$. Sifat pada $\mathbb{S}$ yang disajikan pada Teorema 5 dapat diperluas pada matriks atas $\mathbb{S}$ yang diberikan pada teorema berikut ini.

Teorema 10. (Schutter, 1996) Untuk setiap matriks $M, A, B \in \mathbb{S}^{m \times n}$ berlaku $M \ominus B \nabla A$ jika dan hanya jika $M \nabla A \oplus B$.

Selain itu, sifat reduksi setimbang aljabar max-plus tersimetri pada Teorema 8 dapat diperluas pada pembahasan matriks atas aljabar max-plus tersimetri yang disajikan pada teorema berikut. 
Teorema 11. (Schutter, 1996) Untuk setiap matriks $M, A \in\left(\mathbb{S}^{\vee}\right)^{m \times n}$ berlaku $M \nabla A$ jika dan hanya jika $M=A$

\section{Invers Moore-Penrose pada Matriks Konvensional}

Invers Moore-Penrose pada matriks konvensional muncul pada saat pembahasan matriks berordo $m \times n$. Misalkan $\mathbb{C}$ adalah himpunan semua bilangan kompleks. Invers Moore-Penrose pada matriks konvensional didefinisikan seperti berikut.

Definisi 12. (Ben-Israel \& Greville, 2003) Diberikan matriks $M \in \mathbb{C}^{m \times n}$. Invers Moore-Penrose matriks $M$ adalah matriks $M^{+} \in \mathbb{C}^{n \times m}$ yang memenuhi

1. $M M^{+} M=M$

2. $M^{+} M M^{+}=M^{+}$

3. $\left(M M^{+}\right)^{*}=M M^{+}$

4. $\left(M^{+} M\right)^{*}=M^{+} M$

dengan $*$ adalah transpose konjugat.

Apabila himpunan pembicaraan pada Definisi 12 adalah himpunan bilangan riil maka transpose konjugat cukup diganti dengan transpose. Apabila invers Moore-Penrose pada suatu matriks konvensional ada maka bersifat tunggal. Teorema berikut menjelaskan bahwa invers MoorePenrose dari invers Moore-Penrose suatu matriks adalah matriks itu sendiri.

Teorema 13. (Ben-Israel \& Greville, 2003) Untuk $A \in \mathbb{C}^{m \times n}$ berlaku $\left(A^{+}\right)^{+}=A$

Berikut ini disajikan sifat yang menjelaskan invers Moore-Penrose dari suatu matriks nol. Invers Moore-Penrose dari matriks nol adalah transpose dari matriks nol tersebut, seperti dijelaskan pada teorema berikut ini

Teorema 14. (Ben-Israel \& Greville, 2003) Apabila $A=0 \in \mathbb{C}^{m \times n}$ maka berlaku $A^{+}=0^{T}$.

Teorema berikut menjelaskan invers Moore-Penrose pada perkalian skalar tak nol dengan suatu matriks.

Teorema 15. (Ben-Israel \& Greville, 2003) Untuk skalar tak nol $k$, invers Moore-Penrose dari $k A$ adalah $k^{-1} A^{+}$.

Pada pembahasan matriks konvensional, invers Moore-Penrose dapat digunakan untuk menentukan solusi pendekatan pada sistem persamaan linier $A x=b$, dengan solusi pendekatan tersebut adalah $x=A^{+} b$.

\section{METODE PENELITIAN}

Penelitian ini adalah studi literatur yang sifatnya mengembangkan penelitian yang sudah ada sebelumnya, yakni invers Moore-Penrose pada aljabar konvensional (Ben-Israel and Greville, 2003). Pada penelitian ini dibahas tentang invers Moore-Penrose pada aljabar max-plus tersimetri dengan mengadopsi gagasan invers Moore-Penrose pada aljabar konvensional. Hal ini dilakukan dengan memanfaatkan suatu fungsi yang mengkorespondensikan aljabar max-plus tersimetri dengan aljabar konvensional pada (De \& De, 2002). Adapun langkah-langkah penelitiannya adalah :

1. Melakukan studi literatur (literature review) tentang aljabar max-plus tersimetri dan invers MoorePenrose pada aljabar konvensional.

2. Menunjukkan korespondensi antara $\mathbb{S}$ dengan aljabar konvensional yang akan digunakan untuk menentukan eksistensi invers Moore-Penrose pada matriks atas $\mathbb{S}$.

3. Mendefinisikan invers Moore-Penrose pada matriks atas $\mathbb{S}$ dengan mengadopsi konsep invers Moore-Penrose pada aljabar konvensional.

4. Menunjukkan beberapa sifat invers Moore-Penrose pada matriks atas $\mathbb{S}$.

\section{HASIL DAN PEMBAHASAN}

Pada bagian ini disajikan pembahasan utama dalam artikel ini. Pembahasan meliputi eksistensi invers Moore-Penrose pada matriks atas $\mathbb{S}$ dan beberapa sifat yang digunakan untuk menunjukkan eksistensi tersebut. Selain itu, disajikan beberapa sifat terkait invers Moore-Penrose pada matriks atas $\mathbb{S}$. 
Berikut diberikan definisi fungsi yang digunakan untuk mengkorespondensikan aljabar maxplus tersimetri dengan aljabar konvensional. Fungsi berikut digunakan untuk mengkorespondensikan elemen pada $\mathbb{S}$ dengan suatu elemen pada aljabar konvensional.

Definisi 16. (De \& De, 2002) Fungsi $\mathcal{F}$ dengan domain $\mathbb{S} \times \mathbb{R}_{0} \times \mathbb{R}_{0}^{+}$didefinisikan sebagai

dengan $a \in \mathbb{S}, \mu \in \mathbb{R}_{0}$ dan $s \in \mathbb{R}_{0}^{+}$.

$$
\mathcal{F}(a, \mu, s)=\left\{\begin{array}{cc}
|\mu| e^{a s} & \text { jika } a \in \mathbb{S}^{\oplus} \\
-|\mu| e^{|a|_{\oplus} S} & \text { jika } a \in \mathbb{S}^{\ominus} \\
\mu e^{|a|_{\oplus}} & \text { jika } a \in \mathbb{S}^{\bullet}
\end{array}\right.
$$

Selanjutnya diberikan fungsi yang digunakan untuk mengembalikan hasil korespondensi elemen aljabar max-plus tersimetri pada aljabar konvensional, kembali menjadi bentuk elemen aljabar max-plus tersimetri. Fungsi ini dinamakan sebagai fungsi reverse.

Definisi 17. (De \& De, 2002) Misalkan $f(s) \sim v e^{|a|_{\oplus} s}$ pada persekitaran $\infty$, fungsi balikan (reverse) $\mathcal{R}$ didefinisikan sebagai

$$
\mathcal{R}(f)=\left\{\begin{array}{cc}
|a|_{\oplus} & \text { jika tanda } v \text { adalah positif } \\
\ominus|a|_{\oplus} & \text { jika tanda } v \text { adalah negatif }
\end{array}\right.
$$

Fungsi yang disajikan pada Definisi 16 dan Definisi 17 dapat diperluas pada matriks atas aljabar max-plus tersimetri. Dengan demikian terdapat suatu korespondensi antara matriks atas aljabar max-plus tersimetri dengan matriks konvensional. Teorema berikut menjelaskan hubungan antara matriks atas aljabar max-plus tersimetri dengan matriks bernilai fungsi riil pada aljabar konvensional yang akan digunakan sebagai dasar untuk menunjukkan eksistensi invers MoorePenrose pada matriks atas aljabar max-plus tersimetri.

Teorema 18. (De \& De, 2002) Diberikan $A, B$ dan $C$ masing-masing matriks atas $\mathbb{S}$. Jika terdapat $N_{A}, N_{B}, N_{C}$ sedemikian hingga $\mathcal{F}\left(A, N_{A}, s\right) . \mathcal{F}\left(B, N_{B}, s\right) \sim \mathcal{F}\left(C, N_{C}, s\right), s \rightarrow \infty$ maka $A \otimes B \nabla C$

Berdasarkan Teorema 18, dapat diturunkan beberapa sifat yang akan digunakan untuk menentukan eksistensi invers Moore-Penrose pada matriks atas $\mathbb{S}$. Teorema berikut menjelaskan eksistensi bentuk kesetimbangan $A \otimes X \otimes A \nabla A$ pada matriks atas aljabar max-plus tersimetri.

Teorema 19. Diberikan $A$ dan $X$ masing-masing matriks atas $\mathbb{S}$. Jika terdapat $N_{A}, N_{X}$ sedemikian hingga $\mathcal{F}\left(A, N_{A}, s\right) . \mathcal{F}\left(X, N_{X}, s\right) . \mathcal{F}\left(A, N_{A}, s\right) \sim \mathcal{F}\left(A, N_{A}, s\right)$ untuk $s \rightarrow \infty$ maka berlaku $A \otimes X \otimes A \nabla A$

Bukti. Misalkan $\mathcal{F}\left(A, N_{A}, s\right)$ dan $\mathcal{F}\left(X, N_{X}, s\right)$ masing-masing adalah fungsi bernilai matriks riil yang diperoleh dari Definisi 16. Apabila matriks $\mathcal{F}\left(A, N_{A}, s\right) . \mathcal{F}\left(B, N_{B}, s\right) \sim \mathcal{F}\left(C, N_{C}, s\right), s \rightarrow \infty$ pada Teorema 18 diganti dengan $\mathcal{F}\left(A, N_{A}, s\right) . \mathcal{F}\left(X, N_{X}, s\right) . \mathcal{F}\left(A, N_{A}, s\right) \sim \mathcal{F}\left(A, N_{A}, s\right), s \rightarrow \infty$ maka dapat diperoleh $A \otimes X \otimes A \nabla A$.

Berikut disajikan teorema yang menjelaskan eksistensi bentuk kesetimbangan $X \otimes A \otimes$ $X \nabla X$ pada matriks atas $\mathbb{S}$.

Teorema 20. Diberikan $A$ dan $X$ masing-masing matriks atas $\mathbb{S}$. Apabila terdapat $N_{A}, N_{X}$ sedemikian hingga $\left(X, N_{X}, s\right) . \mathcal{F}\left(A, N_{A}, s\right) . \mathcal{F}\left(X, N_{X}, s\right) \sim \mathcal{F}\left(X, N_{X}, s\right)$ untuk $s \rightarrow \infty$ maka berlaku $X \otimes A \otimes X \nabla X$

Bukti. Misalkan $\mathcal{F}\left(A, N_{A}, s\right)$ dan $\mathcal{F}\left(X, N_{X}, s\right)$ masing-masing adalah fungsi bernilai matriks riil yang diperoleh dari Definisi 16. Dengan mengganti $\mathcal{F}\left(A, N_{A}, s\right) . \mathcal{F}\left(B, N_{B}, s\right) \sim \mathcal{F}\left(C, N_{C}, s\right)$, untuk $s \rightarrow \infty$ pada Teorema 18 dengan $\left(X, N_{X}, s\right) . \mathcal{F}\left(A, N_{A}, s\right) . \mathcal{F}\left(X, N_{X}, s\right) \sim \mathcal{F}\left(X, N_{X}, s\right)$ untuk $s \rightarrow$ $\infty$ maka diperoleh $X \otimes A \otimes X \nabla X$.

Selanjutnya disajikan suatu teorema yang menjelaskan eksistensi bentuk $(A \otimes$ $X)^{T} \nabla A \otimes X$ pada matriks atas aljabar max-plus tersimetri. 
Teorema 21. Diberikan $A$ dan $X$ masing-masing matriks atas $\mathbb{S}$. Jika terdapat $N_{A}, N_{X}$ sedemikian hingga $\left(\mathcal{F}\left(A, N_{A}, s\right) . \mathcal{F}\left(X, N_{X}, s\right)\right)^{T} \sim \mathcal{F}\left(A, N_{A}, s\right) . \mathcal{F}\left(X, N_{X}, s\right)$ untuk $\quad s \rightarrow \infty$ maka berlaku $(A \otimes X)^{T} \nabla A \otimes X$

Bukti. Misalkan $\mathcal{F}\left(A, N_{A}, s\right)$ dan $\mathcal{F}\left(X, N_{X}, s\right)$ masing-masing adalah fungsi bernilai matriks riil yang diperoleh dari Definisi 16. Dengan mengganti $\mathcal{F}\left(A, N_{A}, s\right) . \mathcal{F}\left(B, N_{B}, s\right) \sim \mathcal{F}\left(C, N_{C}, s\right)$, untuk $s \rightarrow \infty$ pada Teorema 18 dengan

$$
\left(\mathcal{F}\left(A, N_{A}, s\right) . \mathcal{F}\left(X, N_{X}, s\right)\right)^{T} \sim \mathcal{F}\left(A, N_{A}, s\right) . \mathcal{F}\left(X, N_{X}, s\right) \text { untuk } s \rightarrow \infty
$$

maka diperoleh $(A \otimes X)^{T} \nabla A \otimes X$.

Teorema berikut menjelaskan eksistensi bentuk kesetimbangan $(X \otimes A)^{T} \nabla X \otimes A$ pada matriks atas aljabar max-plus tersimetri.

Teorema 22. Diberikan $A$ dan $X$ masing-masing matriks atas $\mathbb{S}$. Jika terdapat $N_{A}, N_{X}$ sedemikian hingga $\left(\mathcal{F}\left(X, N_{X}, s\right) . \mathcal{F}\left(A, N_{A}, s\right)\right)^{T} \sim \mathcal{F}\left(X, N_{X}, s\right) . \mathcal{F}\left(A, N_{A}, s\right), s \rightarrow \infty$ maka berlaku $(X \otimes A)^{T} \nabla X \otimes A$

Bukti. Misalkan $\mathcal{F}\left(A, N_{A}, s\right)$ dan $\mathcal{F}\left(X, N_{X}, s\right)$ masing-masing adalah fungsi bernilai matriks riil yang diperoleh dari Definisi 16. Dengan mengganti $\mathcal{F}\left(A, N_{A}, s\right) . \mathcal{F}\left(B, N_{B}, s\right) \sim \mathcal{F}\left(C, N_{C}, s\right)$, untuk $s \rightarrow \infty$ pada Teorema 18 dengan

$$
\left(\mathcal{F}\left(X, N_{X}, s\right) . \mathcal{F}\left(A, N_{A}, s\right)\right)^{T} \sim \mathcal{F}\left(X, N_{X}, s\right) . \mathcal{F}\left(A, N_{A}, s\right) \text { untuk } s \rightarrow \infty
$$

maka diperoleh $(X \otimes A)^{T} \nabla X \otimes A$.

Berikut disajikan contoh untuk menjelaskan Teorema 19, Teorema 20, Teorema 21 dan Teorema 22.

Contoh 23. Diberikan $A=\left[\begin{array}{ccc}1 & 2 & \ominus 1 \\ \ominus 2 & \ominus 3 & 2\end{array}\right]$ dan $X=\left[\begin{array}{cc}-5 & \ominus(-4) \\ -4 & \ominus(-3) \\ \ominus(-5) & -4\end{array}\right]$ masing-masing adalah matriks atas $\mathbb{S}$. Terdapat $N_{A}=\left[\begin{array}{lll}1 & 1 & 1 \\ 1 & 1 & 1\end{array}\right]$ dan $N_{X}=\left[\begin{array}{ll}1 & 1 \\ 1 & 1 \\ 1 & 1\end{array}\right]$ sedemikian hingga

a. $\mathcal{F}\left(A, N_{A}, s\right) . \mathcal{F}\left(X, N_{X}, s\right) . \mathcal{F}\left(A, N_{A}, s\right) \sim\left[\begin{array}{ccc}e^{s} & e^{2 s} & -e^{s} \\ -e^{2 s} & -e^{3 s} & e^{2 s}\end{array}\right]=\mathcal{F}\left(A, N_{A}, s\right), s \rightarrow \infty$

b. $\mathcal{F}\left(X, N_{X}, s\right) . \mathcal{F}\left(A, N_{A}, s\right) . \mathcal{F}\left(X, N_{X}, s\right) \sim\left[\begin{array}{cc}e^{-5 s} & -e^{-4 s} \\ e^{-4 s} & -e^{-3 s} \\ -e^{-5 s} & e^{-4 s}\end{array}\right]=\mathcal{F}\left(X, N_{X}, s\right)$, untuk $s \rightarrow \infty$

C. $\left(\mathcal{F}\left(A, N_{A}, s\right) . \mathcal{F}\left(X, N_{X}, s\right)\right)^{T} \sim\left[\begin{array}{cc}2 e^{-4 s}+e^{-2 s} & -e^{1 s}-2 e^{-3 s} \\ -e^{-s}-2 e^{-3 s} & 1+2 e^{-2 s}\end{array}\right]$ $=\left(\mathcal{F}\left(A, N_{A}, s\right) \cdot \mathcal{F}\left(X, N_{X}, s\right)\right)$, untuk $s \rightarrow \infty$

d. $\left(\mathcal{F}\left(X, N_{X}, s\right) . \mathcal{F}\left(A, N_{A}, s\right)\right)^{T} \sim\left[\begin{array}{ccc}e^{-4 s}+e^{-2 s} & e^{-3 s}+e^{-s} & -e^{-4 s}-e^{-2 s} \\ e^{-3 s}+e^{-s} & e^{-2 s}+1 & -e^{-3 s}-e^{-s} \\ -e^{-4 s}-e^{-2 s} & -e^{-3 s}-e^{-s} & e^{-4 s}+e^{-2 s}\end{array}\right]$ $=\mathcal{F}\left(X, N_{X}, s\right) . \mathcal{F}\left(A, N_{A}, s\right)$, untuk $s \rightarrow \infty$.

Berdasarkan uraian $\mathrm{a}, \mathrm{b}, \mathrm{c}$ dan d maka diperoleh bentuk kesetimbangan

1. $A \otimes X \otimes A \nabla A$

2. $X \otimes A \otimes X \nabla X$

3. $(A \otimes X)^{T} \nabla A \otimes X$

4. $(X \otimes A)^{T} \nabla X \otimes A$.

Pembahasan Teorema 19, Teorema 20, Teorema 21 dan Teorema 22 dilakukan untuk menunjukkan eksistensi bentuk kesetimbangan $A \otimes X \otimes A \nabla A, \quad X \otimes A \otimes X \nabla X, \quad(A \otimes$ $X)^{T} \nabla A \otimes X$ dan $(X \otimes A)^{T} \nabla X \otimes A$ yang akan digunakan untuk mendefinisikan invers MoorePenrose matriks atas aljabar max-plus tersimetri. 
Berikut diberikan definisi inverse Moore-Penrose pada matriks atas aljabar max-plus tersimetri. Pendefinisian ini dilakukan dengan memodifikasi definisi inverse Moore-Penrose pada matriks konvensional, yakni dengan merubah relasi "sama dengan" pada aljabar konvensional menjadi relasi "setimbang" (balance) pada aljabar max-plus tersimetri.

Definisi 24. Diberikan $M \in \mathbb{S}^{m \times n}$. Invers Moore-Penrose matriks $M$ adalah matriks $M^{+}$berukuran $n \times m$ yang memenuhi

1. $M \otimes M^{+} \otimes M \nabla M$

2. $M^{+} \otimes M \otimes M^{+} \nabla M^{+}$

3. $\left(M \otimes M^{+}\right)^{T} \nabla M \otimes M^{+}$

4. $\left(M^{+} \otimes M\right)^{T} \nabla M^{+} \otimes M$

Berdasarkan Contoh 23 diperoleh bahwa matriks $X$ memenuhi syarat invers Moore-Penrose untuk matriks $A$. Dengan demikian, matriks $X=\left[\begin{array}{cc}-5 & \ominus(-4) \\ -4 & \ominus(-3) \\ \ominus(-5) & -4\end{array}\right]$ adalah invers MoorePenrose untuk matriks $A=\left[\begin{array}{ccc}1 & 2 & \ominus 1 \\ \ominus 2 & \ominus 3 & 2\end{array}\right]$

Pada pembahasan matriks konvensional, apabila suatu matriks $M$ memiliki invers MoorePenrose $\mathrm{M}^{+}$maka eksistensi $\mathrm{M}^{+}$adalah tunggal. Sementara itu, pada pembahasan matriks atas aljabar max-plus tersimetri, eksistensi dari invers Moore-Penrose dari suatu matriks belum tentu tunggal. Teorema berikut menjelaskan ketidaktunggalan invers Moore-Penrose dari suatu matriks atas aljabar max-plus tersimetri.

Teorema 25. Diberikan $M^{+}$adalah invers Moore-Penrose untuk $M$. Jika $M^{+}$adalah matriks bertanda maka setiap matriks $B$ dengan $B \nabla M^{+}$adalah invers Moore-Penrose untuk $M$.

Bukti. Karena $B \nabla A^{+}$dan $A^{+}$adalah matriks bertanda maka $A^{+}$dapat disubstitusi lemah dengan matriks $B$. Dengan demikian diperoleh

1. $M \otimes B \otimes M \nabla M$

2. $B \otimes M \otimes B \nabla B$

3. $(M \otimes B)^{T} \nabla M \otimes B$

4. $(B \otimes M)^{T} \nabla B \otimes M$.

Jadi $B$ memenuhi syarat invers Moore-Penrose untuk matriks $M$. Dengan demikian $B$ juga merupakan invers Moore-Penrose untuk matriks $M$.

Contoh berikut menjelaskan ketidaktunggalan invers Moore-Penrose dari suatu matriks atas aljabar max-plus tersimetri.

Contoh 26. Matriks $X=\left[\begin{array}{cc}-5 & \ominus(-4) \\ -4 & \ominus(-3) \\ \ominus(-5) & -4\end{array}\right]$ adalah invers Moore-Penrose untuk matriks $A=$ $\left[\begin{array}{ccc}1 & 2 & \ominus_{1}^{1} \\ \ominus 2 & \ominus 3 & 2\end{array}\right]$. Apabila diambil matriks $\quad X^{\prime}=\left[\begin{array}{cc}2 & \ominus(-4) \\ -4 & \ominus 1^{\bullet} \\ \ominus(-5) & 0^{\bullet}\end{array}\right] \quad$ dengan $X^{\prime} \nabla\left[\begin{array}{cc}-5 & \ominus(-4) \\ -4 & \ominus(-3) \\ \ominus(-5) & -4\end{array}\right]=X$ maka matriks $X^{\prime}$ juga merupakan invers Moore-Penrose untuk matriks $A$.

Teorema berikut menjelaskan syarat cukup suatu matriks $X$ menjadi invers Moore-Penrose dari suatu matriks $A$. 
Teorema 27. Diberikan $A$ dan $X$ masing-masing matriks atas $\mathbb{S}$. Jika terdapat $N_{A}, N_{X}$ sedemikian hingga

1. $\mathcal{F}\left(A, N_{A}, s\right) . \mathcal{F}\left(X, N_{X}, s\right) . \mathcal{F}\left(A, N_{A}, s\right) \sim \mathcal{F}\left(A, N_{A}, s\right), s \rightarrow \infty$

2. $\mathcal{F}\left(X, N_{X}, s\right) . \mathcal{F}\left(A, N_{A}, s\right) . \mathcal{F}\left(X, N_{X}, s\right) \sim \mathcal{F}\left(X, N_{X}, s\right), s \rightarrow \infty$

3. $\left(\mathcal{F}\left(A, N_{A}, s\right) . \mathcal{F}\left(X, N_{X}, s\right)\right)^{T} \sim \mathcal{F}\left(A, N_{A}, s\right) . \mathcal{F}\left(X, N_{X}, s\right), s \rightarrow \infty$

4. $\left(\mathcal{F}\left(X, N_{X}, s\right) . \mathcal{F}\left(A, N_{A}, s\right)\right)^{T} \sim \mathcal{F}\left(X, N_{X}, s\right) . \mathcal{F}\left(A, N_{A}, s\right), s \rightarrow \infty$

maka $X$ adalah invers Moore-Penrose dari $A$.

Bukti. Karena terdapat $N_{A}, N_{X}$ sedemikian hingga

1. $\mathcal{F}\left(A, N_{A}, s\right) . \mathcal{F}\left(X, N_{X}, s\right) . \mathcal{F}\left(A, N_{A}, s\right) \sim \mathcal{F}\left(A, N_{A}, s\right), s \rightarrow \infty$

2. $\mathcal{F}\left(X, N_{X}, s\right) . \mathcal{F}\left(A, N_{A}, s\right) . \mathcal{F}\left(X, N_{X}, s\right) \sim \mathcal{F}\left(X, N_{X}, s\right), s \rightarrow \infty$

3. $\left(\mathcal{F}\left(A, N_{A}, s\right) . \mathcal{F}\left(X, N_{X}, s\right)\right)^{T} \sim \mathcal{F}\left(A, N_{A}, s\right) . \mathcal{F}\left(X, N_{X}, s\right), s \rightarrow \infty$

4. $\left(\mathcal{F}\left(X, N_{X}, s\right) . \mathcal{F}\left(A, N_{A}, s\right)\right)^{T} \sim \mathcal{F}\left(X, N_{X}, s\right) . \mathcal{F}\left(A, N_{A}, s\right), s \rightarrow \infty$

maka berdasarkan Teorema 19, Teorema 20, Teorema 21 dan Teorema 22, berturut-turut diperoleh

1. $A \otimes X \otimes A \nabla A$

2. $X \otimes A \otimes X \nabla X$

3. $(A \otimes X)^{T} \nabla A \otimes X$

4. $(X \otimes A)^{T} \nabla X \otimes A$.

Dengan demikian $X$ memenuhi syarat invers Moore-Penrose untuk $A$. Jadi $X$ adalah invers Moore-Penrose untuk $A$.

Selanjutnya dibahas beberapa sifat invers Moore-Penrose pada matriks atas $\mathbb{S}$. Berikut disajikan teorema yang menjelaskan bahwa suatu matriks adalah invers Moore-Penrose dari invers Moore-Penrose matriks tersebut.

Teorema 28. Apabila $M^{+}$adalah invers Moore-Penrose $M$, maka $M$ adalah invers Moore-Penrose untuk $M^{+}$.

Bukti. Apabila syarat pada Definisi 24 disajikan dengan urutan

1. $M^{+} \otimes M \otimes M^{+} \nabla M^{+}$

2. $M \otimes M^{+} \otimes M \nabla M$

3. $\left(M^{+} \otimes M\right)^{T} \nabla M^{+} \otimes M$

4. $\left(M \otimes M^{+}\right)^{T} \nabla M \otimes M^{+}$

maka $M$ memenuhi syarat invers Moore-Penrose untuk $M^{+}$. Dengan demikian, $M$ adalah invers Moore-Penrose untuk $\mathrm{M}^{+}$.

Contoh berikut memberikan penjelasan makna dari Teorema 28, yakni suatu matriks adalah invers Moore-Penrose dari invers Moore-Penrose matriks tersebut.

Contoh 29. Matriks $X=\left[\begin{array}{cc}-5 & \ominus(-4) \\ -4 & \ominus(-3) \\ \ominus(-5) & -4\end{array}\right]$ adalah invers Moore-Penrose untuk matriks $A=$ $\left[\begin{array}{ccc}1 & 2 & \ominus 1 \\ \ominus 2 & \ominus 3 & 2\end{array}\right]$. Dengan demikian, matriks $A$ adalah invers Moore-Penrose untuk matriks $X$.

Berikut disajikan teorema yang menjelaskan invers Moore-Penrose dari matriks identitas terhadap operasi penjumlahan (matriks nol) pada aljabar max-plus tersimetri.

Teorema 30. Untuk $M=\varepsilon_{m \times n}$ maka matriks $X=\varepsilon_{n \times m}$ adalah invers Moore-Penrose untuk matriks $A$.

Bukti. Diperhatikan bahwa perkalian matriks nol $\mathcal{E}$ akan selalu menghasilkan matriks nol juga.

1. $M \otimes X \otimes M=M \nabla M$

2. $X \otimes M \otimes X=X \nabla X$ 
3. $(M \otimes X)^{T}=M \otimes X \nabla M \otimes X$

4. $(X \otimes M)^{T}=X \otimes M \nabla X \otimes M$

Jadi $X=\varepsilon_{n \times m}$ adalah invers Moore-Penrose untuk matriks $M$.

Akibat 31. Untuk $M=\varepsilon_{m \times n}$ maka setiap matriks setimbang (balanced matrix) $X^{\prime}{ }_{n \times m}$ adalah invers Moore-Penrose untuk matriks $M=\mathcal{E}_{m \times n}$.

Bukti. Karena $X_{n \times m}^{\prime}$ adalah matriks setimbang berarti setiap entri pada $X_{n \times m}^{\prime}$ adalah elemen setimbang. Selanjutnya, karena $\varepsilon_{n \times m}$ adalah matriks bertanda dan $X^{\prime} \nabla \varepsilon_{n \times m}$, maka matriks $\varepsilon_{n \times m}$ dapat disubstitusi dengan $X^{\prime}$. Dengan demikian diperoleh matriks $X^{\prime}$ memenuhi syarat untuk invers Moore-Penrose untuk matriks $M=\varepsilon_{m \times n}$.

Contoh berikut menjelaskan invers Moore-Penrose dari matriks nol pada aljabar max-plus tersimetri pada Teorema 30.

Contoh 32. Diberikan matriks $A=\left[\begin{array}{lll}\mathcal{E} & \mathcal{E} & \mathcal{\varepsilon} \\ \mathcal{E} & \mathcal{E} & \varepsilon\end{array}\right]$. Diperhatikan bahwa $X=\left[\begin{array}{ll}\mathcal{E} & \mathcal{E} \\ \mathcal{E} & \mathcal{E} \\ \mathcal{E} & \mathcal{E}\end{array}\right]$ adalah invers Moore-Penrose untuk matriks $A$. Jika diambil $X^{\prime}=\left[\begin{array}{cc}\ominus 3^{\bullet} & 1^{\bullet} \\ \mathcal{E} & \mathcal{E} \\ \mathcal{E} & \ominus(-1)^{\bullet}\end{array}\right] \nabla\left[\begin{array}{ll}\mathcal{E} & \mathcal{E} \\ \mathcal{E} & \mathcal{\varepsilon} \\ \mathcal{E} & \mathcal{\varepsilon}\end{array}\right]=X$ maka $X^{\prime}$ juga merupakan invers Moore-Penrose untuk matriks $A=\left[\begin{array}{lll}\mathcal{E} & \mathcal{E} & \mathcal{E} \\ \mathcal{E} & \mathcal{E} & \mathcal{E}\end{array}\right]$.

Berikut disajikan teorema yang menjelaskan invers Moore-Penrose dari hasil perkalian skalar matriks pada aljabar max-plus tersimetri.

Teorema 33. Diberikan $M^{+}$adalah invers Moore-Penrose untuk $M \in \mathbb{S}^{m \times n}$ dan $k \in \mathbb{S}_{*}^{\vee}$. Matriks $k^{-1} \otimes M^{+}$adalah invers Moore-Penrose untuk matriks $k \otimes M$.

Bukti. Diperhatikan bahwa

1. $(k \otimes M) \otimes\left(k^{-1} \otimes M^{+}\right) \otimes(k \otimes M)=k \otimes k^{-1} \otimes k \otimes M \otimes M^{+} \otimes M$ $=e \otimes k \otimes M \otimes M^{+} \otimes M=k \otimes M \otimes M^{+} \otimes M \nabla k \otimes M$

2. $\left(k^{-1} \otimes M^{+}\right) \otimes(k \otimes M) \otimes\left(k^{-1} \otimes M^{+}\right)=k^{-1} \otimes k \otimes k^{-1} \otimes M^{+} \otimes M \otimes M^{+}$ $=e \otimes k^{-1} \otimes M^{+} \otimes M \otimes M^{+}=k^{-1} \otimes M^{+} \otimes M \otimes M^{+} \nabla k^{-1} \otimes M^{+}$

3. $\left((k \otimes M) \otimes\left(k^{-1} \otimes M^{+}\right)\right)^{T}=\left(k \otimes k^{-1} \otimes M \otimes M^{+}\right)^{T}=\left(e \otimes M \otimes M^{+}\right)^{T}$ $=\left(M \otimes M^{+}\right)^{T} \nabla M \otimes M^{+}=e \otimes M \otimes M^{+}=k \otimes k^{-1} \otimes M \otimes M^{+}$ $=(k \otimes M) \otimes\left(k^{-1} \otimes M^{+}\right)$

4. $\left(\left(k^{-1} \otimes M^{+}\right) \otimes(k \otimes M)\right)^{T}=\left(k^{-1} \otimes k \otimes M^{+} \otimes M\right)^{T}=\left(e \otimes M^{+} \otimes M\right)^{T}$ $=\left(M^{+} \otimes M\right)^{T} \nabla M^{+} \otimes M=e \otimes M^{+} \otimes M=k^{-1} \otimes k \otimes M^{+} \otimes M$ $=\left(k^{-1} \otimes M^{+}\right) \otimes(k \otimes M)$.

Jadi $k^{-1} \otimes M^{+}$adalah invers Moore-Penrose untuk matriks $k \otimes M$.

Sifat-sifat invers Moore-Penrose pada matriks aljabar konvensional dapat diadopsi pada pembahasan invers Moore-Penrose pada matriks aljabar max-plus tersimetri. Pengadopsian sifat tersebut tidak bisa dilakukan secara langsung, akan tetapi harus dilakukan dengan memperhatikan sifat substitusi lemah pada aljabar max-plus tersimetri.

Berikut disajikan contoh kasus aplikasi invers Moore-Penrose pada penyelesaian sistem kesetimbangan linier atas aljabar max-plus tersimetri. Diberikan permasalahan sistem linier

$$
\left[\begin{array}{cc}
0 & -4 \\
3 & 2
\end{array}\right] \otimes\left[\begin{array}{l}
x_{1} \\
x_{2}
\end{array}\right] \oplus\left[\begin{array}{c}
1 \\
-5
\end{array}\right]=\left[\begin{array}{cc}
-1 & 1 \\
\varepsilon & 2
\end{array}\right] \otimes\left[\begin{array}{l}
x_{1} \\
x_{2}
\end{array}\right] \oplus\left[\begin{array}{l}
2 \\
7
\end{array}\right] .
$$

Permasalahan tersebut berkorespondensi dengan sistem kesetimbangan linier Crammer

$$
\left[\begin{array}{cc}
0 & \ominus \\
3 & 2^{\bullet}
\end{array}\right] \otimes\left[\begin{array}{l}
x_{1} \\
x_{2}
\end{array}\right] \nabla\left[\begin{array}{l}
2 \\
7
\end{array}\right]
$$


Diperhatikan bahwa matriks $A^{+}=\left[\begin{array}{cc}(-2)^{\bullet} & -3 \\ \ominus(-1) & -4\end{array}\right]$ adalah invers Moore-Penrose untuk matriks $A=\left[\begin{array}{cc}0 & \ominus \\ 3 & 2^{\bullet}\end{array}\right]$. Selanjutnya $\left[\begin{array}{l}x_{1} \\ x_{2}\end{array}\right] \nabla A^{+} \otimes\left[\begin{array}{l}2 \\ 7\end{array}\right]=\left[\begin{array}{l}4 \\ 3\end{array}\right]$ adalah solusi sistem kesetimbangan linier Crammer.

\section{KESIMPULAN}

Invers Moore-Penrose pada matriks atas aljabar max-plus tersimetri dapat didefinisikan mirip seperti pada matriks konvensional, yakni dengan mengganti relasi "sama dengan" pada matriks konvensional dengan relasi "setimbang (balance)" pada matriks atas aljabar max-plus tersimetri. Apabila matriks $M^{+}$adalah invers Moore-Penrose dari $M$ pada aljabar max-plus tersimetri, maka eksistensi dari $M^{+}$tidak tunggal. Beberapa sifat invers Moore-Penrose matriks atas aljabar max-plus tersimetri adaah

1. Matriks $M$ adalah invers Moore-Penrose untuk matriks $M^{+}$

2. Setiap matriks setimbang (balanced matrix) adalah invers Moore-Penrose untuk matriks nol

3. Untuk suatu skalar bertanda tak nol $k$, matriks $k^{-1} \otimes M^{+}$adalah invers Moore-Penrose untuk matriks $k \otimes M$.

\section{REKOMENDASI}

Penelitian selanjutnya berpotensi dapat dilakukan pada konstruksi invers Moore-Penrose dengan menggunakan dekomposisi matriks atas aljabar max-plus tersimetri. Selain itu, juga dapat dilakukan pada aplikasi invers Moore-Penrose pada sistem kesetimbangan linier atas aljabar maxplus tersimetri.

\section{UCAPAN TERIMAKASIH}

Ucapan terima kasih disampaikan kepada Universitas Jenderal Soedirman yang telah memfasilitasi peneliti untuk dapat melakukan penelitian ini.

\section{DAFTAR PUSTAKA}

Baccelli, F. (ed.). (1992). Synchronization and linearity: an algebra for discrete event systems. Chichester; New York: Wiley (Wiley series in probability and mathematical statistics).

Bapat, R. B., Bhaskara, R. K. P. S., \& Prasad, K. M. (1990). Generalized inverses over integral domains. Linear Algebra and Its Applications, 140, 181-196. doi: 10.1016/00243795(90)90229-6.

Beezer, R. A. (2015). A first course in linear algebra. Gig Harbor, Wash: Congruent Press. Available at: https://open.umn.edu/opentextbooks/BookDetail.aspx?bookld=5 (Accessed: 10 September 2021).

Ben-Israel, A. \& Greville, T. N. E. (2003). Generalized inverses: theory and applications. 2nd ed. New York: Springer (CMS books in mathematics, 15).

Bhaskara, R. K. P. S. (1983). On generalized inverses of matrices over integral domains. Linear Algebra and Its Applications, 49, 179-189. doi:10.1016/0024-3795(83)90102-7.

Campbell, S. L., \& Meyer, C. D. (2009). Generalized inverses of linear transformations. Philadelphia: Society for Industrial and Applied Mathematics (Classics in applied mathematics, 56). 
De, S. B., \& De, B. (2002). The QR decomposition and the singular value decomposition in the symmetrized max-plus algebra revisited. SIAM Review, 44(3), 417-454. doi:10.1137/S00361445024039.

Farid, F. O., Khan, I. A., \& Wang, Q. W. (2013). On matrices over an arbitrary semiring and their generalized inverses. Linear Algebra and Its Applications, 439(7), 2085-2105. doi:10.1016/j.laa.2013.06.002.

Golub, G. H., \& Van. L. C. F. (2013). Matrix computations. Fourth edition. Baltimore: The Johns Hopkins University Press (Johns Hopkins studies in the mathematical sciences).

Hogben, L. (ed.). (2007). Handbook of linear algebra. Boca Raton: Chapman \& Hall/CRC (Discrete mathematics and its applications).

Manjunatha, P. K., \& Bapat, R. B. (1992). The generalized moore-penrose inverse. Linear Algebra and Its Applications, 165, 59-69. doi:10.1016/0024-3795(92)90229-4.

Pearl, M. H. (1968). Generalized inverses of matrices with entries taken from an arbitrary field. Linear Algebra and Its Applications, 1(4), 571-587. doi:10.1016/0024-3795(68)90028-1.

Pradhan, R., \& Pal, M. (2014). Some results on generalized inverse of intuitionistic fuzzy matrices. Fuzzy Information and Engineering, 6(2), 133-145. doi:10.1016/j.fiae.2014.08.001.

Schutter, B. de. (1996). Max-algebraic system theory for discrete event systems.

Xu, S., \& Chen, J. (2019). The Moore-penrose inverse in rings with involution. Filomat, 33(18), 57915802. doi:10.2298/FIL1918791X. 